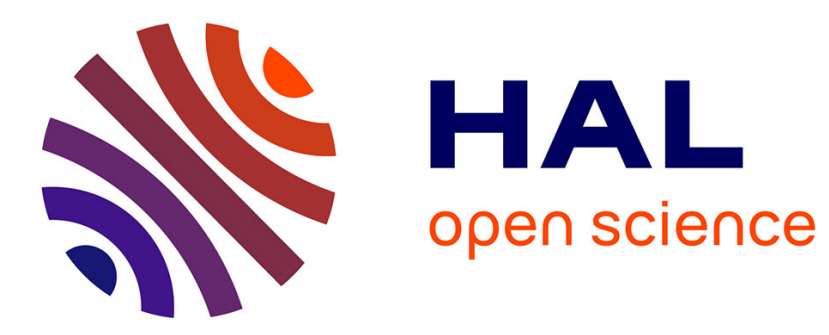

\title{
Active deformation mechanisms responsible for ductility and flow stress dependence on temperature in TiAl alloys
}

\author{
M. Morris
}

\section{- To cite this version:}

M. Morris. Active deformation mechanisms responsible for ductility and flow stress dependence on temperature in TiAl alloys. Journal de Physique IV Proceedings, 1993, 03 (C7), pp.C7-365-C7-370. 10.1051/jp4:1993757 . jpa-00252176

HAL Id: jpa-00252176

https://hal.science/jpa-00252176

Submitted on 1 Jan 1993

HAL is a multi-disciplinary open access archive for the deposit and dissemination of scientific research documents, whether they are published or not. The documents may come from teaching and research institutions in France or abroad, or from public or private research centers.
L'archive ouverte pluridisciplinaire HAL, est destinée au dépôt et à la diffusion de documents scientifiques de niveau recherche, publiés ou non, émanant des établissements d'enseignement et de recherche français ou étrangers, des laboratoires publics ou privés. 


\title{
Active deformation mechanisms responsible for ductility and flow stress dependence on temperature in TiAl alloys
}

\author{
M.A. MORRIS
}

Institute of Structural Metallurgy, University of Neuchâtel, Av. Bellevaux 51, 2000 Neuchâtel, Switzerland

\begin{abstract}
The active dislocation mechanisms responsible for the deformation process of two phase TiAl alloys have been analysed and their influence on ductility and strength have been interpreted as a function of deformation temperature. The measured values of misfit strain between the $\alpha_{2}$ and the $\gamma$ phases have been shown to be responsible for the accumulation of dislocations that occurs at their interfaces. The stress concentrations that build up at these sites lead to microcrack formation and determine the lack of ductility of the materials. The anomalous strengthening effect that is observed with increasing temperature has been shown to be determined by the activity of ordinary $1 / 2<110$ ] dislocations that are generated from twin intersections. The increased jog density produced by the increased number of emitted dislocations up to the peak temperature leads to the strengthening mechanism observed.
\end{abstract}

\section{INTRODUCTION}

Much of the research carried out in TiAl intermetallic compounds has been concerned with fundamental studies of dislocation structures in single phase materials [1-4]. The basic properties of these Al-rich alloys are inherent brittleness at room temperature with ductility and flow stress increasing at high temperature [5-7] which have been explained by different authors in terms of the low dislocation mobility of both types $1 / 2<110]$ and $<101]$ obtained after deformation at room temperature [8-11]. The sessile configurations of $<101$ ] dislocations observed dissociated as screw segments or with directions at $60^{\circ}$ from screw orientation have extensively been studied by Hug et al. $[3,4]$. These authors concluded that the anomalous peak in flow stress observed with increasing temperature was due to the cross-slip of $1 / 2<101]$ dislocations from $\{111\}$ to $\{100\}$ planes where these segments become locked.

More recent studies have been concerned wth Ti-rich alloys consisting of two phases $\gamma+\alpha_{2}\left(\mathrm{Ti}_{3} \mathrm{Al}\right.$ $\left(\mathrm{DO}_{19}\right)$ and $\mathrm{TiAl}(\mathrm{L} 10)$ structures) which present better room temperature ductility [12]. Some studies of the dislocation configurations of $\gamma$-TiAl in these two phase alloys have shown that at room temperature only glide of $1 / 2<110]$ and $1 / 2<112]$ dislocations and twinning of the type $\{111\}<11 \overline{2}]$ is observed [13]. This implies that the dislocation configurations responsible for ductility depend on the initial microstructure and this has been shown to change not just as a function of aluminium content but also as a function of initial heat treatment [14]. Also the temperature dependence of the flow stress has been shown to be a function of both aluminium content as well as of initial microstructure[7,15]. Therefore it is necessary that for each alloy condition the dislocation configuration and their interactions be known before being able to define which mechanism is responsible for the ductility or for the anomalous increase in flow stress observed with increasing temperature.

Other contributions to improvement in ductility of two phase alloys have been obtained by additions of alloying elements such as chromium, vanadium and niobium under different conditions of thermomechanical treatments $[16,17]$. However, details of dislocation configurations responsible for these improved properties are not yet known. In the present study, two alloys of composition $\mathrm{Ti}-48 \mathrm{Al}$ and $\mathrm{Ti}$ $47.5 \mathrm{Al}-2.5 \mathrm{Cr}(\mathrm{at} \%)$ with small grain sizes and lamellar structures have been compared in terms of the dislocation configurations present before and after deformation. An attempt has been made to identify the role played by the lamellar structure with respect to the deformation mechanisms observed, including the influence of dislocation dissociations and reactions on the effect of thermally induced strengthening at elevated temperatures. 


\section{EXPERIMENTAL TECHNIOUES}

The nominal compositions of the alloys used for this study were Ti-48Al and Ti-47.5Al-2.5Cr (at\%). They were prepared by the Osprey deposition technique and were supplied by AluSuisse after HIP at $1100^{\circ} \mathrm{C}$. Detailed description of the technique and of the general improvements that result in the more homogeneous microstructures of these alloys with respect to conventional casting techniques have been published elsewhere [18] Microstructural analysis of the annealed and deformed materials was performed by transmission electron microscopy (TEM) using a Philips CM12 microscope equipped with energydispersive spectroscopy facilities (EDS). Dislocation analysis was made from projected images obtained by tilting the specimens to different known orientations (zone axes) using a kikuchi map corresponding to the L10 structure. From each zone axis different diffraction vectors were chosen to obtain invisibility under some contrast conditions. Weak beam images were taken using the $\mathbf{g :} \mathbf{3 g}, \mathbf{4 g}$ conditions for different diffraction vectors. X-ray diffraction analysis was performed from both alloys in order to measure the lattice parameters and to compare the effect of the chromium addition on the tetragonality of the L10 lattice and on the misfit strain between the $\alpha_{2}$ and the $\gamma$ phases. A Philips EPD 1880 diffractometer was used.

Surface studies were carried out by scanning electron microscopy (SEM) using a Cambridge 360 Stereoscan microscope also equipped with EDS facilities. Quantitative analysis of the volume fractions of the different phases present was made using an image analyser Cambridge Quantimet 720.

The deformed specimens studied were produced by bend and compression tests were also performed from rectangular bars and cylindrical specimens respectively. The compression tests were carried out as a function of testing temperature between -196 (in liquid nitrogen) and $700^{\circ} \mathrm{C}$ (in an argon atmosphere).

\section{RESULTS AND DISCUSSION}

The two alloys used for this study had the same equiaxed distribution of grains with fully lamellar structure of the $\gamma$ and $\alpha_{2}$ The grain sizes have been measured as $40 \mu \mathrm{m}$ in the binary alloy and $80 \mu \mathrm{m}$ in the chromium containing alloy. The volume fraction of $\alpha_{2}$ lamellae was measured from SEM micrographs obtained using atomic number contrast as the example of figure 1 . The distribution of the $\alpha_{2}$ phase is observed as bright lamellae due to the higher atomic number of the Ti-rich phase. The darker $\gamma$ phase regions are rather globular at zones around grain boundaries and triple junctions but they are lamellar at the grain interiors. EDS chemical analysis confirmed the compositions of these phases. The measured volume fraction of $\alpha_{2}$ lamellae was $22 \%$ in the binary alloy decreasing to $15 \%$ in the chromium containing alloy. The micrograph of figure 1 also shows the presence of small particles distributed homogeneously in both alloys. These have been observed to be aluminium oxide as the EDS analysis only detected the presence of oxygen and aluminium. The measured volume fraction of these particles was $2 \%$ in both alloys. From the $\mathrm{X}$-ray data it has been possible to measure the value of the misfit parameter at the interface between the $\mathrm{DO}_{19}\left(\alpha_{2}\right)$ and the L1o $(\gamma)$ phases. The misfit strain between the two phases is defined by the misfit parameter, $\varepsilon$, given by :

$$
\varepsilon=\frac{\left[\mathrm{d}_{\gamma^{110}}-\mathrm{d}_{\alpha 2}{ }^{11 \overline{2} 0}\right]}{\mathrm{d}_{\gamma}{ }^{110}}
$$

where $\mathrm{d}_{\gamma}{ }^{110}$ and $\mathrm{d}_{\alpha 2}{ }^{11 \overline{2} 0}$ are the d-spacings for the (110) and (1120) planes of the $\gamma$ and $\alpha_{2}$ phases respectively.Using the $\mathrm{d}$-spacings obtained from the $\mathrm{X}$-ray data, we have obtained a variation of the misfit parameter between 0.021 for the binary alloy to 0.017 in the chromium containing alloy. Therefore the presence of chromium appears to reduce the misfit strain between the two phases such that accommodation at the $\alpha_{2} / \gamma$ interface will require a lower density of misfit dislocations. The presence of dislocation networks at the $\alpha_{2} / \gamma$ interfaces has been confirmed by TEM as can be seen in figure 2 . In this figure we see the distribution of $\alpha_{2}$ lamellae within the $\gamma$ matrix as observed by phase contrast (bright field) in the as-received alloys, together with details from an interface of the $\alpha_{2}$ lamellae seen under weak beam conditions (2b). At this interface we see a regular arrangement of two dislocation families that constitute part of a hexagonal network which helps accommodate the strain across $\{111\}_{\gamma}$ planes. Within the TiAl matrix there exist alternate $\gamma$ lamellae separated by $\gamma / \gamma$ interfaces which also contain dislocations. These lamellae were formed during cooling by the nucleation of domains of specific orientations with respect to the hexagonal phase present at high temperatures. In our alloys specific rotation relationships between neighbouring $\gamma$ regions have been analysed and two types of unambiguous rotation relationships have been identified, namely that produced by a $90^{\circ}$ rotation around a $<010$ ] axis and that produced by a $120^{\circ}$ rotation around $a<111>$ axis. Some slight misorientations of $2-3^{\circ}$ from those exact rotations are also 

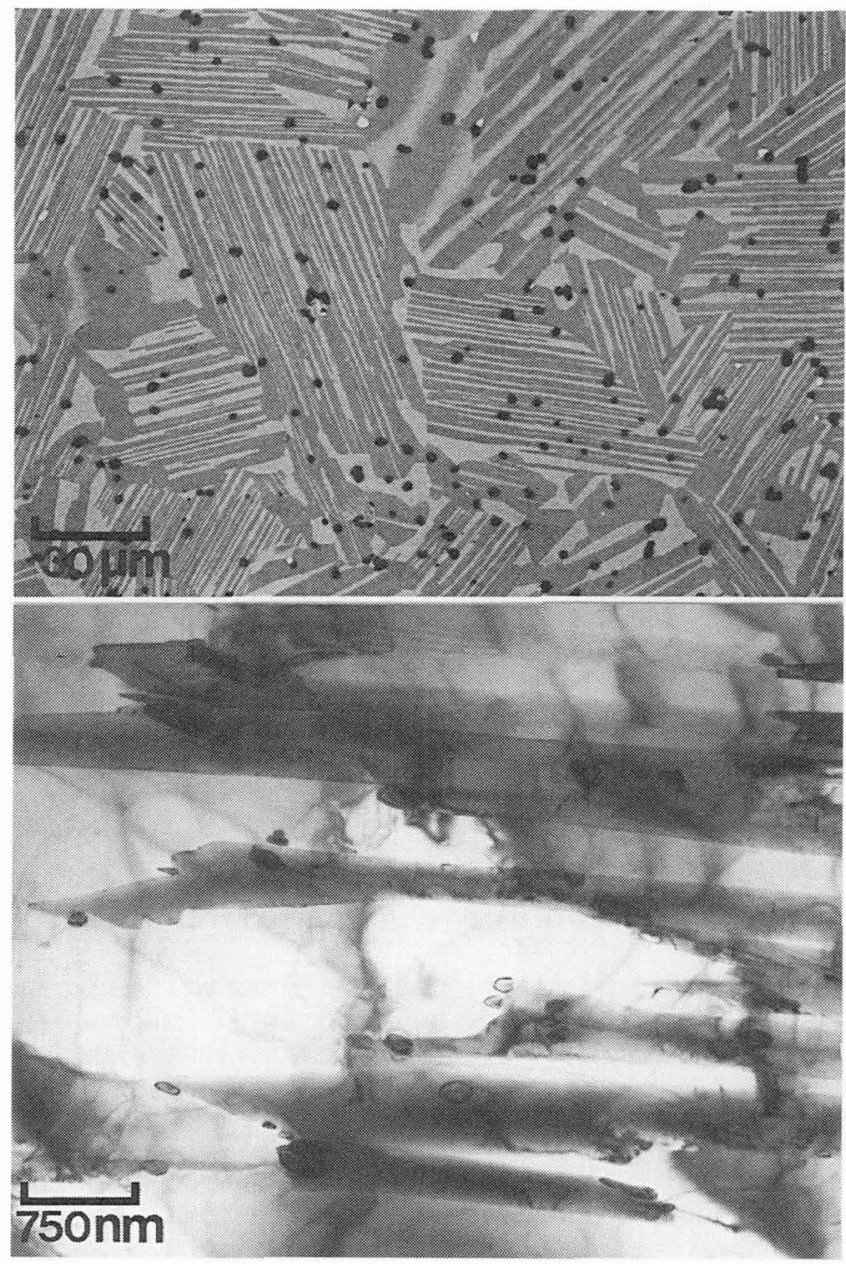

Figure 1. Example of microstructure confirming the distribution of lamella phase (bright) within the darker $\gamma$ regi typical for both alloys studied.

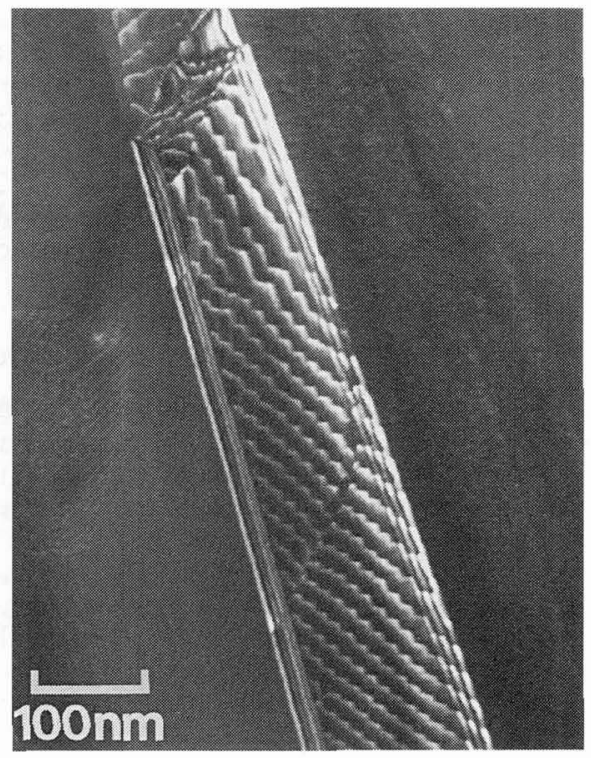

Figure 2. a) Distribution of $\alpha_{2}$ lamellae within the $\gamma$ matrix seen by phase contrast in the TEM.b) One of these lamellae is shown under weak beam conditions and a dislocation network is observed at the interface.

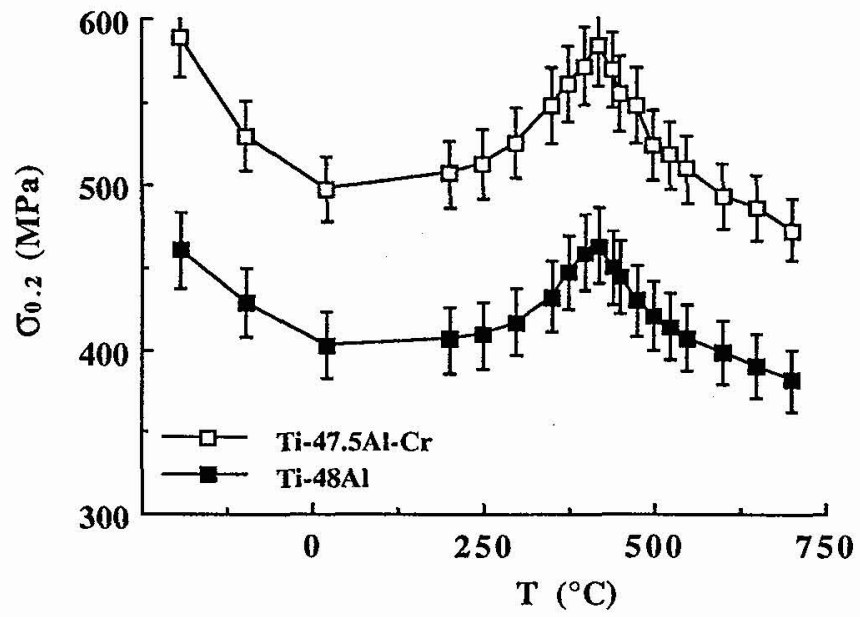

Figure 3. Plots of flow stress at $0.2 \%$ strain as a function of deformation temperature for both alloys. Note that two high values are observed, namely at -196 and at $420^{\circ} \mathrm{C}$. 
present as evidenced by small deviations from the exact zone axis in each case. which are responsible for the presence of many dislocations at the $\gamma / \gamma$ interfaces. The described microstructures, in particular the rotation relationships and the dislocations present at the interfaces between different domains will influence the propagation of slip between neighbouring $\gamma$ regions. Absorption or emission of dislocations can occur at the interfaces by dislocation reactions which will allow new slip systems to be active and to ensure compatibility of deformation according to the domain orientation. The annealed alloys contained a dislocation substructure which was created at high temperature during the cooling process due to the thermal stresses created between the two phases [19]. The two alloys examined have very similar dislocation microstructures in the annealed state, namely a large majority of single dislocations with some superdislocations of the type $1 / 2<112$ ] leading to sessile configurations by reactions during intersection of the $1 / 2<110]$ segments.

From the compression tests performed as a function of temperature the values of flow stress have been measured at $0.2 \%$ strain and figure 3 shows plots these values for the two alloys. We note that both materials show an anomalous peak in flow stress at a temperature of $420^{\circ} \mathrm{C}$. However the chromium containing alloy exhibits higher yield stress values at all temperatures. Bend tests were also performed from our alloys in order to assess their ductility under tension. Maximum total strains of $0.1 \%$ and $0.2 \%$ were achieved in the binary and the chromium containing alloy respectively. Although the latter was slightly more ductile, the formation of cracks at the $\alpha_{2} / \gamma$ interfaces were observed in both alloys during the stages prior to failure. The first microcracks were observed after $2 \%$ strain in compression, however they were already present after 0.1 and $0.2 \%$ strain during the bend tests of the binary and chromium containing alloy respectively. Figure 4 shows surface observations of these cracks after bending or compression tests. It is evident that the lack of ductility is due to the concentration of stress leading to microcracks at the $\alpha_{2} / \gamma$ interface.

The active mechanisms of deformation in the $\gamma$ phase at room temperature are characterized by:

a) Twinning activity produced by the passage of Shockley partials of the type $1 / 6<112$ ] on [111] planes

b) Glide of single $1 / 2<110]$ dislocations and

c) Activity of superdislocations of either $<101]$ or $1 / 2<112$ ] type. Although these major characteristics are the same in both alloys, the basic differences can be defined as a much higher density of deformation twins in the ternary alloy and the different types of superdislocations which are active in each material. While the binary alloy contains more superdislocation of the type $<101]$, the chromium containing alloy deforms by glide of $1 / 2<112$ ] dislocations which trail faulted dipoles. Detailed analysis made from the characteristic dissociations presented by the different dislocation configurations, have been described previously [19]. During deformation at low temperature $\left(-196^{\circ} \mathrm{C}\right)$ much twinning and superdislocations activity is again observed. Large dissociations are seen indicating that the dislocations cores are very relaxed at these temperatures. Details concerning analysis of the dislocations seen at low temperatures have been published elsewhere [20]. On the other hand, the decrease in flow stress observed between $-196^{\circ} \mathrm{C}$ and room temperature shows a normal trend, characteristic of extra dislocation mobility with increase in temperature and we will not discuss the mechanisms in any more detail here.

The major aspect concerning the anomalous strengthening observed between room temperature and $420^{\circ} \mathrm{C}$, are the characteristic dislocation configurations seen at high temperatures. Both at temperatures of $400^{\circ} \mathrm{C}$ and $600^{\circ} \mathrm{C}$ the active mechanisms of deformation in both alloys are twinning and glide of single $1 / 2$ $<110]$ dislocations. In particular, many of the latter are seen emitted at twin intersections. Figures 5 shows examples of cross-twinning events for the two alloys. These ordinary $1 / 2<110$ ] dislocations appear to be active on both types of $(001)$ and $\{111\}$ planes. Also expansion of the $1 / 2<110]$ loops occurs by bowing out the edge segments while the screw parts become longer and rather straight. Also common at this temperature is the presence of pinning points along the dislocation lines and in particular along the screw segments together with a number of debris characteristic of annihilation processes.

After deformation at $600^{\circ} \mathrm{C}$, much twinning activity and single $1 / 2<110$ ] dislocations are also seen, while the emission of the latter at twin intersections continues to be very active. However at this stage there is evidence that climbing processes are very active since since $1 / 2<110$ ] edge dislocations are contained on many different planes [20].Figure 6 shows examples of this activity for both alloys.

Therefore we have confirmed from the deformed microstructures that the disappearance of superdislocations occurs between 200 and $600^{\circ} \mathrm{C}$ such that the only active deformation mechanisms at the temperatures below and above the peak are twinning and glide of $1 / 2<110$ ] dislocations. These results 

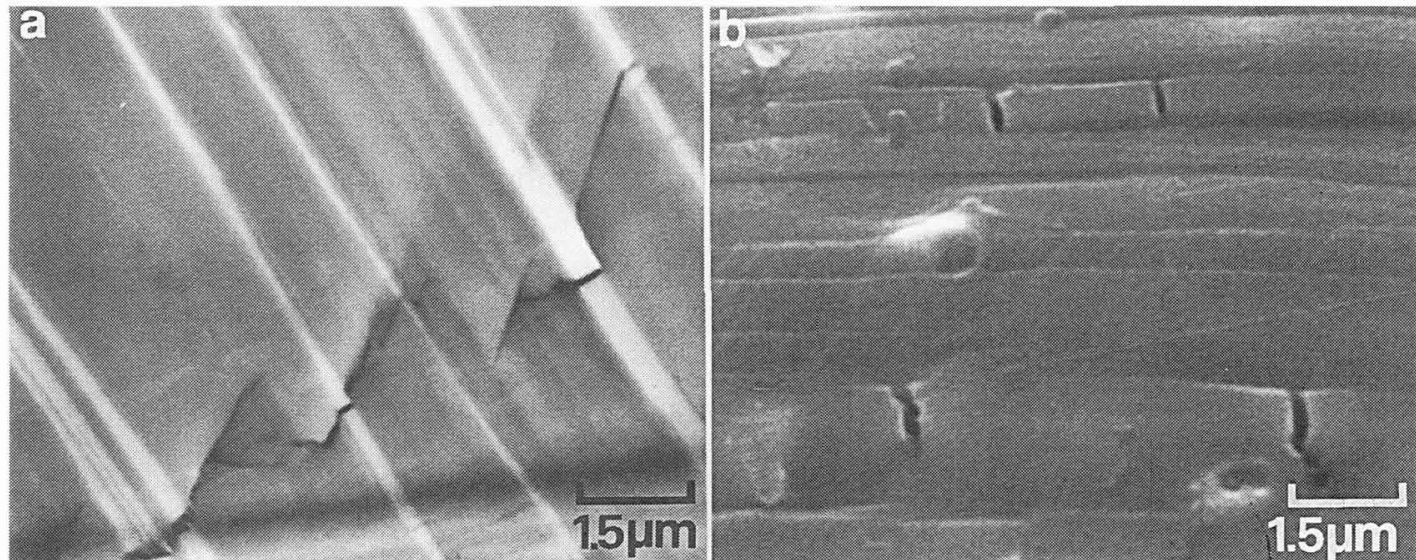

Figure 4. a) Example of microcracks observed after $2 \%$ strain in compressed samples of the binary alloy, b) crack initiation at the $\alpha_{2} / \gamma$ interfaces and propagation through several lamellae during bend tests
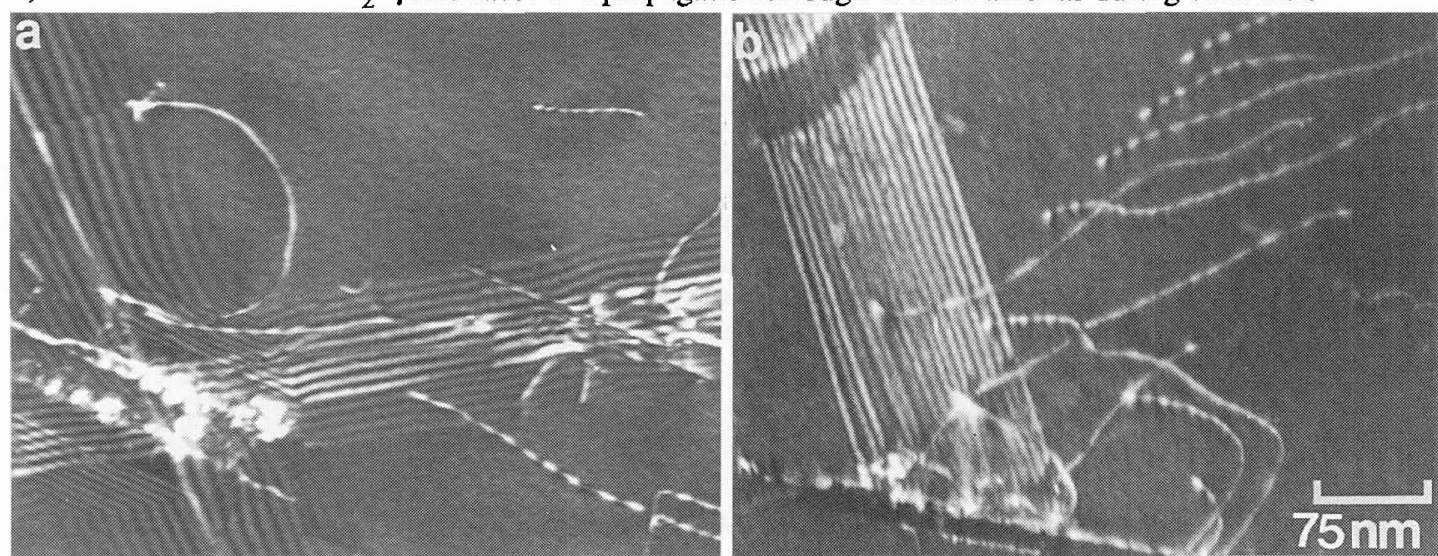

Figure 5. a) Example of dislocation emission at twin intersections observel after deformation of the binary alloy at $400^{\circ} \mathrm{C}$.b) Pile-up of $1 / 2<110$ ] dislocations being emitted from twin intersections after deformation of the ternary alloy at $400^{\circ} \mathrm{C}$. The bowed segments have edge character while the straight ones are screw.
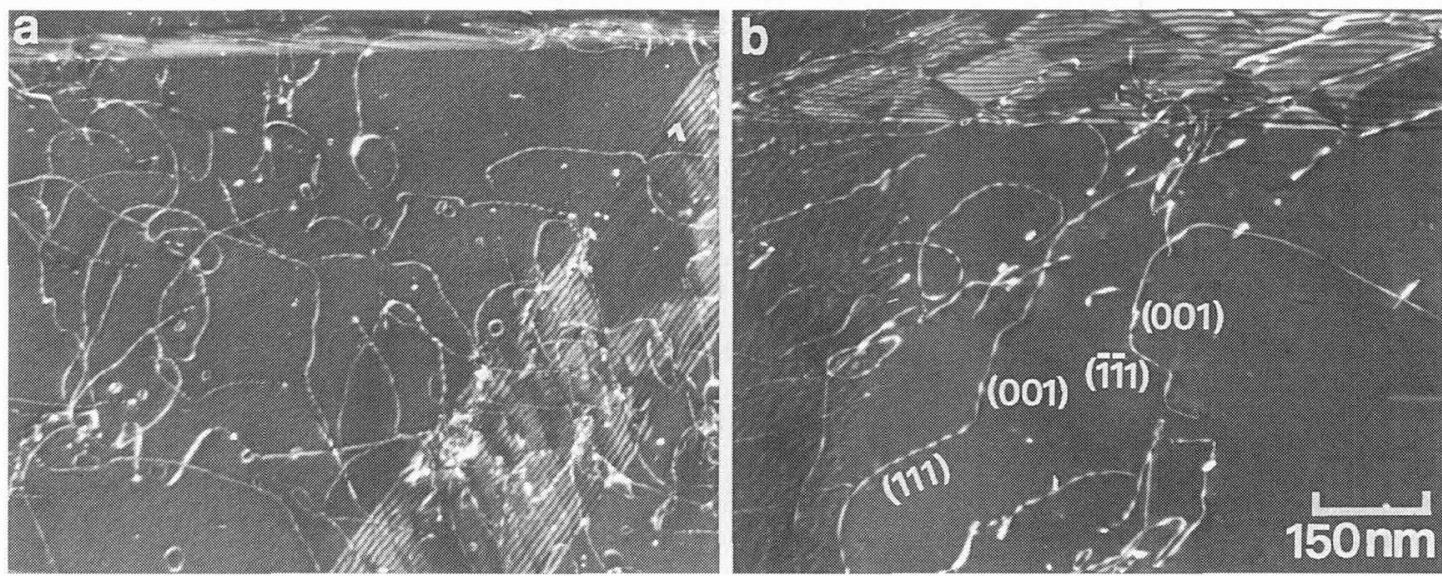

Figure 6. a) Example of twins and climb activity from $1 / 2<110$ ] dislocations observed after deformation of the ternary alloy at $600^{\circ} \mathrm{C}$.b) Similar activity observed in the binary alloy under the same condition. 
confirm those already observed by Greenberg et al. [21] in single phase Al-rich alloys. In the case of single phase alloys the anomalous increase in flow stress with temperature has been interpreted by Hug et al. [4] as being due to a blocking process experienced by dissociated $<101$ ] superdislocations after crossslip to (100) planes where the APB energy is lower. In our alloys the absence of superdislocations after deformation between $200^{\circ} \mathrm{C}$ and $600^{\circ} \mathrm{C}$ indicate that the anomalous increase of flow stress with increasing temperature cannot be attributed to a mechanism concerning dissociation or cross-slip of superdislocations. Indeed even at room temperature many of the $<101$ ] dislocations seen appear rather immobile, their dissociations being responsible for their lack of mobility [19]. However, even long straight immobile superdislocations are not seen at the temperatures at which the anomalous strengthening effect is seen and therefore it must be concluded that the mechanism responsible for the increase in flow stress should be attributed to single dislocations only.

An anomalous increase in flow stress with increasing temperature indicates the formation of a blocking barrier by a mechanism that requires thermal activation. Only at temperatures sufficiently high (above the peak value) the barrier can be destroyed by a thermally activated process which corresponds to the unblocking mechanism. In order to obtain information on these thermally activated processes, we have calculated the activation energies by measuring the thermally activated stress increase at different testing temperatures just below and above the peak [20]. In the case of the blocking mechanism the energy obtained was $4 \times 10^{-20} \mathrm{~J} /$ atom (approximately $0.25 \mathrm{eV}$ ) for both alloys. For the unblocking process the calculated activation energy was slightly higher, corresponding to $6 \times 10^{-20} \mathrm{~J} /$ atom $(\approx 0.4 \mathrm{eV})$ for both alloys. From the observed dislocation configurations, i.e. the presence of long ordinary $1 / 2<110]$ screw segments that appear jogged or pinned at certain points along their length, together with the increased number of debris observed at high temperature we can suggest that the anomalous strengthening effect is due to a jog dragging mechanism controlling the deformation process. If an increased density of jogs is obtained by thermal activation, a larger force will be required in order for the dislocation to propagate. This requires that jog formation is the thermally activated mechanism responsible for the strengthening effect. An increase in the number of jogs with increasing temperature has been explained by the observed increased number of $1 / 2<110$ ] dislocations seen emitted from twin intersections at $400^{\circ} \mathrm{C}$. This emission appears to occur to relax stress concentrations existing at twin intersections, as evidenced in the case of twins intersecting the $\alpha_{2}$ interface, where dislocation emission cannot occur, and the stress concentration leads to microcrack formation [20].

\section{REFERENCES}

1.Schehtman D., Blackburn M.J. and Lipsitt H.A. (1974), Metall. Trans., 5, 1374.

2.Vasudevan V.K., Stucke M.A., Court S.A. and Fraser H.L. (1989), Phil. Mag. Letters,59, 299.

3.Hug G., Loiseau A. and Lasalmonie A.(1986), Phil. Mag.,54, 47.

4.Hug G., Loiseau A. and Veyssière P. (1988), Phil. Mag., 57, 499.

5.Lipsitt H.A.,Schechtman D. and Schafik R.E. (1975), Metall. Trans., 6A, 1991.

6.Kawabata T., Kanai T. and Izumi O. (1985), Acta Metall.,33, 1355.

7.Huang S. C. (1987), Scripta Metall., 22, 1985.

8.Court S.A., Vasudevan V.K. and Fraser H.L.(1990),Phil. Mag., 61, 141.

9.Greenberg B.A., Antonova O.V., Indenbaum V.N., Karkina L.A., Notkin A.B.,Ponomarev M.V. and Smirnov L.V. (1991), Acta Metall. Mat., 39, 233.

10.Whang S.H. and Hahn Y.D. (1990),Scripta Metall. Mat., 24, 485.

11.Greenberg B.A., Anisimov V.I., Gornostirev Y.N. and Taluts G.G. (1988), Scripta Metall, 22,859.

12.Huang S.C. and Hall E.L. (1991), Metall. Trans.A, 22,427.

13.Inui H., Nakamura A., Oh M.H. and Yamaguchi (1992), Phil. Mag., 66, 557.

14. Kim Y-W. (1989), Journal of Metals, 41, 24.

15. Huang S.C. and Hall E.L. (1991),Scripta Metall. Mat., 25, 1805.

16. Kawabata T., Tamura T. and Izumi O.(1989), High Temperature Ordered Intermetallic Alloys III, Editors C.T. Liu, A. I.Taub and N. S. Stoloff, MRS 133, 329.

17.Kim Y-W. (1992), Acta Metall. Mat., 40, 1121.

18. Morris D.G., Morris M.A., Gunter S., Leboeuf M., and Hollrigl G., (1992), Scripta Metall. Mat.., 19.Morris M.A., Phil. Mag.(1992), in press.

20.Morris M.A., Phil. Mag.(1993), in press.

21.Greenberg B.A., Antonova O.V., Karkina L.A., Notkin A.B.,Ponomarev A.V., (1992), Acta Metall. Mat., 40,815 . 